\title{
Das Auto der Zukunft: ein geklebter Materialmix?
}

Ingenieure aus Werkstoff- und Klebtechnik diskutieren am 16. und 17. April 2013 in Stuttgart, wie sich neue Technologien aus der Forschung auf die Entwicklung energieeffizienter Modelle in der Praxis übertragen lassen.

eichte Autos sind gut für die Umwelt,

_denn sie verbrauchen weniger Energie. Was einfach klingt, ist schwere Entwicklungsarbeit. Denn leichte Materialien müssen auch energieeffizient zu produzieren und recyceln sein. Verlässliche Fügeverfahren wie die Klebtechnik sollen diese so verbinden, dass die $\mathrm{CO}_{2}$-Bilanz insgesamt positiv ausfällt. Wie sich nachhaltiger Ressourcenschutz im $\mathrm{Au}^{-}$ tomobilbau durch den Dialog von Werkstoff- und Klebtechnikern einerseits und Vertretern aus Wissenschaft und Industrie andererseits am besten erreichen lässt, diskutieren Experten auf zwei Fachtagungen, die erstmals parallel stattfinden.

Längst ist ein Auto mehr als ein Metall-Fahrzeug, das von Schrauben und Nieten zusammengehalten wird. Carbonfasern, Werkstoffe aus Alumi- nium und Magnesium oder neuartige Glasmaterialien sind im Automobilbau keine Ausnahme mehr. Gleichzeitig gewinnen organische Werkstoffe an Bedeutung, und auch die Metalle als klassische Materialien können mehr leisten als in der Vergangenheit. Dieser Mix stellt neue Anforderungen an die Fügeverfahren. Besonders gut eignen sich Klebstoffe bei diesem sogenannten Multi-Material-Design. So sind in einem modernen Auto bereits mehr als 15 Kilogramm Klebstoff verarbeitet. Die zentrale Frage lautet, welches Material wo am effektivsten und zu vertretbaren Kosten eingesetzt werden kann.

Leichtbau ist ein Thema, das die gesamte Wertschöpfungskette in der Automobilindustrie durchzieht wie ein roter Faden: von der Konstruk- tion und Entwicklung über die Produktion bis hin zur Fertigung. Damit neue Konzepte erfolgreich werden, müssen alle Beteiligten in den Dialog miteinander treten. Um diesen wichtigen Austausch zu fördern, finden die beiden Tagungen „Werkstoffe im Automobilbau“ in Kooperation mit dem Deutschen Zentrum für Luft- und Raumfahrt und „Fertigungstechnologie Kleben“ in Kooperation mit dem Fraunhofer IFAM erstmals parallel statt. Auf diese Weise können die Experten sich aus beiden Branchen-Angeboten ihr persönliches Programm zusammenstellen. Beide Veranstaltungen von Springer Vieweg finden am 16. und 17. April 2013 im Stuttgarter Maritim Hotel statt.

Weitere Infos: www.adhaesionlive.de

\section{Veranstaltungen April -Mai}

\begin{tabular}{|c|c|c|c|}
\hline Termin & Ort & Thema & Veranstalter \\
\hline 16.-17.04.2013 & Stuttgart & $\begin{array}{l}\text { FTK - Fertigungstechnologie Kleben } \\
2013\end{array}$ & $\begin{array}{l}\text { ADHÄSIONlive } \\
\text { Tel: }+49(0) 611-7878676 \\
\text { www.adhaesionlive.de }\end{array}$ \\
\hline 16.-17.04.2013 & Stuttgart & Werkstoffe im Automobilbau & $\begin{array}{l}\text { ATZlive } \\
\text { Tel: }+49(0) 611.7878-274 \\
\text { www.ATZlive.de }\end{array}$ \\
\hline 16.-18.04.2013 & Nürnberg & SMT Hybrid Packaging & $\begin{array}{l}\text { Mesago Messe Frankfurt GmbH } \\
\text { Tel. +49 } 71161946-0 \\
\text { www.mesago.de }\end{array}$ \\
\hline $24 .-25.04 .2013$ & $\begin{array}{l}\text { Mülheim an der } \\
\text { Ruhr }\end{array}$ & ift-Fachtagung Holzfenster 2013 & $\begin{array}{l}\text { ift Rosenheim GmbH } \\
\text { Tel: }+49 \text { (80 31) 261-2151 } \\
\text { www.ift-rosenheim.de }\end{array}$ \\
\hline $06 .-10.05 .2013$ & Hannover & Ligna & $\begin{array}{l}\text { Deutsche Messe } \\
\text { Tel.: +49 (0) } 51189-0 \\
\text { www.hannovermesse.de }\end{array}$ \\
\hline 13.-14.05.2013 & Memmingen & $\begin{array}{l}\text { TechnoBond: Fachtagung industrielle } \\
\text { Klebtechnik }\end{array}$ & $\begin{array}{l}\text { Ostbayerisches Technologie-Transfer-Institut e.V. (OTTI) } \\
\text { Tel.: +49 (0) } 9412968834 \\
\text { www.otti.de/veranstaltung/id/technobond-fachtagung- } \\
\text { industrielle-klebtechnik.html }\end{array}$ \\
\hline
\end{tabular}

